\title{
Prevalence and risk factors of brucellosis in man and domestic animals: A review
}

\author{
P. H. Bamaiyi \\ Department of Public Health, School of Allied Health Sciences Ishaka, Kampala International University, P.O. Box 20000 \\ Kampala, Uganda. \\ Corresponding author: P. H. Bamaiyi, e-mail: pwaveno.bamaiyi@kiu.ac.ug \\ Received: 24-05-2016, Accepted: 08-09-2016, Published online: 27-09-2016
}

doi: 10.14202/IJOH.2016.29-34 How to cite this article: Bamaiyi PH. Prevalence and risk factors of brucellosis in man and domestic animals: A review. Int J One Health 2016;2:29-34.

\begin{abstract}
Brucellosis is the most common worldwide zoonosis with 500,000 new cases every year in humans and infections in millions of animals. This infection is mainly acquired by humans through consumption of unpasteurized milk and milk products from infected animals. Exposure can also occur occupationally in those who work closely with animals through contact with aborted fetuses and reproductive secretions. Animals acquire the infection from other infected animals through direct contact and vertical transmission. This infection is prevalent in all continents of the world except Antarctica, but its impact is more felt in developing countries where it is endemic in animals and humans. In certain developed countries where the disease was eradicated, there seem to be a re-emergence of the disease as the disease appears to claim more territory. The risk factors of the disease may vary from country to country and region to region, but most risk factors are similar. Consumption of unpasteurized milk and milk products plays a very important role in the transmission of this infection from animals to humans, in addition to direct contact with infected animals and their secretions. The best way to control this ubiquitous infection is through the One Health approach which involves human health, animal health, and environmental health. This paper reviews the prevalence of brucellosis in some countries in various continents of the world and highlights the risk factors responsible for the persistence of this infection in animals and humans with a view to proffering solution to this age-old zoonosis that has defied eradication for many generations in many parts of the world.
\end{abstract}

Keywords: animals, brucellosis, human, prevalence, risk factors.

\section{Introduction}

Brucellosis is a very old zoonosis and recent evidence from Egyptian ancient skeletons has shown that this disease has been existing since at least 750 $\mathrm{BC}$ [1]. Brucellosis also known by other names such as Malta fever, intermittent fever, Bang's disease, undulant fever, Gibraltar fever, Mediterranean fever, contagious abortion, Maltese fever, Crimean fever, and rock fever is a bacterial zoonotic infection caused by a Gram-negative coccobacilli bacteria that infect almost all species of domestic animals and man. The disease is caused by several species of Brucellae including Brucella abortus, Brucella melitensis, Brucella ovis, Brucella suis, Brucella canis, Brucella microti, Brucella inopinata, Brucella Ceti, and Brucella pinnipedialis [2-4].

The gold standard for Brucella identification still remains the isolation of the organism from samples and one of the best methods of diagnosing brucellosis is by the use of polymerase chain reaction (PCR) [5]. However, serological diagnosis is still the most common means of diagnosis of the disease in a herd or a population.

Copyright: Bamaiyi. This article is an open access article distributed under the terms of the Creative Commons Attribution 4.0 International License (http://creativecommons.org/licenses/ by/4.0/), which permits unrestricted use, distribution, and reproduction in any medium, provided you give appropriate credit to the original author(s) and the source, provide a link to the Creative Commons license, and indicate if changes were made. The Creative Commons Public Domain Dedication waiver (http:// creativecommons.org/ publicdomain/zero/1.0/) applies to the data made available in this article, unless otherwise stated.
Brucellosis used to be mainly an occupational hazard associated disease, but in recent years increase in travel and a renewed interest in trying some form of raw exotic milk has increased the prevalence of the disease among travelers to endemic countries and has been associated with some outbreaks of brucellosis in the human population [6-9]. About 500,000 new cases of brucellosis are reported annually [10].

This paper reviews the prevalence of brucellosis in man and domestic animals from different countries and risk factors that must be avoided or minimized to control or prevent infection. This review showed that the battle to control brucellosis is a long fight with bacteria that are rapidly evolving and spreading in a modern world. New strategies must be put in place if the fight against these bacteria must be won.

\section{Human Brucellosis}

Accurate data on human cases of brucellosis are lacking from many countries especially developing countries, and the lack of active data leads to underestimation of the burden of the disease [11] which may negatively affect control and prevention measures that could be instituted. A very important key to controlling brucellosis in humans is controlling it in animals [10]. But in most developing countries, there is widespread prevalence of the disease in animals which sustains it in the human population.

\section{Africa}

Brucellosis is widespread and the prevalence of brucellosis varies from one country and region in 
Africa to the other [12]. In Nigeria, the infection has been reported in $24.1 \%$ of abattoir workers in Abuja, Nigeria with occupation and eating raw meat as risk factors [13]. In Ethiopia, 34.1\% of patients from Borana, 29.4\% from Hamer, and 3\% from Metema were seropositive for brucellosis using the Brucella immunoglobulin $\mathrm{M}$ (IgM) IgG lateral flow assay [14]. There was no difference in seropositivity in terms of sexes, and all the seropositive individuals from Borana and Metema suffered symptoms of arthralgia and back pain. Living near an animal shelter had odds ratio (OR): 3.59 , keeping animals on the yard had OR: 5.16, attending animals on the pasture had OR: 5.14, milking animals had OR: 2.07, ingestion of raw milk had OR: 3.33 and consumption of fresh cheese had OR: 5.39 which were all significantly associated with brucellosis infection [14]. In rural northern Tanzania, the risk of brucellosis was significantly associated with helping an aborting animal, proximity to other households, and people of the Christian religion [15]. A retrospective study of brucellosis involving 652 cases using Brucella agglutination test between June 2004 and May 2006 in Uganda found that living in urban areas was a risk factor for brucellosis more than living in peri-urban and rural areas due to a higher risk of unpasteurized milk consumption [16].

\section{Asia and the Middle East}

In a study in Iran, the most common source of infection with brucellosis was the consumption of unpasteurized fresh cheese, and occupational exposure was recorded in $52.1 \%$ of patients [17]. In Malaysia, the risk factors of brucellosis included occupation, age and drinking unpasteurized milk with farmers having 7.19 times the odds of brucellosis when compared to non-farmers $(90 \%$ confidence interval [CI]: 1.16-44.71); those 40 years and below having 7.16 times the odds of brucellosis than those above 40 years (90\% CI: 1.16-44.41) and those who consumed unpasteurized milk have 4.5 times the odds of having brucellosis than those who do not consume (90\% CI: 1.03-19.15) [18].

In a study of brucellosis in pregnant women in Saudi Arabia, the incidence of spontaneous abortion in the first and second trimesters was found to be $43 \%$, and intrauterine fetal death was $2 \%$ [19].

The nation of Israel appears to suffer from endemic brucellosis especially southern Israel close to the Bedouin tribes who live in close proximity to their herds and consume lots of unpasteurized milk and dairy products. Some inhabitants of Israel, such as the Ethiopian Jews, do not raise animals or consume dairy products but yet are increasingly becoming infected with brucellosis in recent years. An important often overlooked risk factor for brucellosis is the traditional ritual slaughter of animals that is commonly practiced among Ethiopian Jews in Israel in which the animal is slaughtered, skinned, eviscerated and the meat is minced thereby exposing those involved to the infectious pathogen [20]. Countries in the Middle East such as Iraq and Egypt are noted as endemic for brucellosis in animals as well as humans [21].

\section{North America}

Brucellosis has been reported in different groups, classes of people, and different countries in North America especially the developing nations in this continent. Many of the human cases of brucellosis in this region of the world like in many parts of the world are acquired through consumption of unpasteurized milk and milk products such as cheese which are gotten from animals infected with brucellosis. In the United States, an estimated 839 new cases of brucellosis illness are reported annually with 55 hospitalization and 1 death [22]. Laboratory acquired cases of brucellosis are increasingly becoming a concern, with up to 5 cases between 2008 and 2011, as it demonstrates violations in safety standards in laboratories or some degree of negligence on the side of laboratory staff [23].

\section{South America}

In a study in Brazil, $13 \%$ of an urban poor population was positive for $B$. abortus and $4.6 \%$ was positive for $B$. canis and individuals older than 45 were significantly associated with infection [24]. Normally, there are fewer cases of $B$. canis in humans reported around the world. The reported prevalence of $B$. canis has epidemiological and public health implications because of the closeness of dogs to man both in rural and urban populations. In many developing countries, man and dogs live side by side with little attention paid to hygiene and the health of the dog; this increases the possibility of transmission of the infection from dogs to the human population.

\section{Europe}

Although brucellosis is not as widespread in Europe as it is in Africa, Asia, and the Middle East, it is still a significant disease of public health importance. Cross-border molecular tracing has confirmed brucellosis to be a zoonosis of public health importance in Europe [25]. In Germany in the years 20022003, there were confirmed reports of brucellosis with 30 isolates from humans confirmed as $B$. melitensis and 1 isolate confirmed as $B$. suis [26].

There seem to have been a decrease in the prevalence of brucellosis in Italy from the year 1998 to 2010, during which 8483 cases were notified in Italy. An epidemiologic model to correct the underreporting of cases showed that the number of cases should have ranged from 41,821 to 155,324 implying a more severe picture of brucellosis in humans in Italy than envisaged by the surveillance system [27].

An analysis of Brucella isolates from humans in Denmark using multiple-locus variable number tandem repeat analysis revealed that the isolates belonged to an existing defined "East Mediterranean" B. melitensis group. This implies that cases of brucellosis in Denmark were imported from other countries [28]. 


\section{Australia}

In Townsville, Northern Australia, the major etiologic agent of brucellosis was B. suis which was acquired mostly through feral pig hunting (94\%) with humans showing common brucellosis symptoms of fever, arthralgia, and fatigue [29]. From the year 1991 to 2012, there was an annual average of 34 notifications of human brucellosis in Australia [30]. Australia is not considered endemic for human brucellosis, but the persistence of sporadic reports of the infection implies that it may be endemic in the animal population or the disease persists as a result of movement of people from endemic countries to Australia or vice versa and the consumption of infected products.

\section{Animal Brucellosis}

Brucellosis has been reported from different species of animals worldwide including marine mammals [31]. It is one of the most economically important diseases of animals worldwide [32], yet, information related to the prevalence of brucellosis is still sparse from the developing world and there is need to address this paucity of literature from the developing world because eradication of brucellosis would not be lasting if many other parts of the world are still struggling with endemic brucellosis [33]. The transboundary risks of brucellosis are real as it is known to be imported along with animals from one country to another making it an important zoonotic transboundary disease [25,34]. The control of brucellosis in animals is central to the control and prevention of the infection in humans because human to human transmission of the infection is very rare, so the bacteria are usually transmitted from animals to man. Breaking this transmission link would be pivotal in the control, prevention, and eradication of brucellosis.

\section{Africa}

Sex was not significantly associated with brucellosis in cattle and goats in an arid region of Nigeria and keeping goats and cattle together increased the risk of brucellosis in the goats as goats were found to have antibodies against $B$. abortus in addition to $B$. melitensis [35]. This finding conveys the importance of keeping cattle separate from goats to minimize the risk of cross-transmission of infection from one species to another. Some reports have found goats living with cattle to be infected with $B$. abortus and cattle with $B$. melitensis.

In a study of brucellosis in cattle 907, serum samples were collected in Ivory Coast for analysis using a parallel interpretation, rose bengal test and indirect enzyme linked immunosorbent assay results revealed 10.3\% (95\% CI: 8.4-12.4) of the cattle had antibodies against Brucella in the study area. The logistic regression analysis showed that brucellosis seropositivity was related to age and herd size. Cattle above 5 years of age showed higher odds for seropositivity (OR: 2.8; 95\% CI: 1.3-6.4) compared to cattle under 3 years of age. In the same manner, the odds of brucellosis seropositivity for herds that had more than 100 cattle was 3.3 (95\% CI: 1.2-8.9) times higher compared to those with $<50$ cattle [36].

A study of brucellosis in Angola using the rose Bengal plate test showed a prevalence of $14.96 \%$ out of 1344 samples taken from cattle with herd prevalence reaching $40.10 \%$. Some risk factors associated with brucellosis in cattle in Angola included shortage of facilities for isolation of infected animals (OR: 6.66; 95\% CI: 1.16-38.34), purpose of production different from meat (OR: 3.13; 95\% CI: 1.07-9.19), abortions (OR: 3.98; 95\% CI: 1.92-8.28), female infertility, and neonatal mortality (OR: 3.07; 95\% CI: 1.42-6.65) [37].

A retrospective study of 17,359 samples from Uganda analyzed serologically between 1998 and 2008 showed the overall seroprevalence was $10 \%$ with humans and bovine species having the highest seroprevalence of $16 \%$ and $12 \%$, respectively. Majority of the positive brucellosis results were in the cattle corridor with $\mathrm{p}=0.399$. The trends of brucellosis seroprevalence decreased over time in the different animal species but were the highest in bovine with $\mathrm{p}=0.043$ [38]. It appeared that in Uganda bovine brucellosis is more closely associated with risk of human infection than other forms of brucellosis.

A study in Ethiopia showed the prevalence of brucellosis in cattle, camels and goats as $10.6 \%, 2.2 \%$ and $1.9 \%$, respectively, with brucellosis contributing significantly to abortions in these animals. Keeping more than two animal species at household level was revealed as the risk factor for cattle (OR: 3.1; 95\% CI: 1.2-7.9) and camel (OR: 5.3; 95\% CI: 1.2-23.5) suggesting the possibility of cross brucellosis transmission under mixed herding conditions [39].

\section{Asia and the Middle East}

In a study in Jordan, the estimated true seroprevalence was found to be $18.1 \%$ (95\% CI: 11-25.3) (cattle-only herds), 22.2\% (95\% CI: 16.5-28.8) (sheep flocks), 45.4\% (95\% CI: 30.3-61.6) (goat herds), 70.4\% (95\% CI: 55.5-84.9) (mixed sheep-goat flocks), 34.3\% (95\% CI: 28.4-40.4) (all small ruminant flocks), and 38.5\% (95\% CI: 24.3-51.8) (mixed herds of cattle and small ruminants) and the identified risk factors in Jordan included lending/borrowing rams (OR: 8.9; 95\% CI: 3.0-26.1), feeding aborted material to dogs (OR: $8.0 ; 95 \%$ CI: 3.5-18.1) the presence of goats (OR: 6.9; 95\% CI: 3.1-15.4), introducing new animals to the flock (OR: 5.8; 95\% CI: 2.5-13.6), and a large flock size (OR: 2.2; 95\% CI: 1.0-4.6) [40]. The prevalence of brucellosis in goats in Malaysia for 10 years (2000 to 2009) was found to be $0.91 \%$ at animal level and $7.09 \%$ at farm level [41]. The risk factors of brucellosis in Malaysian goats were found to be the introduction of new animals (OR: $5.25 ; 90 \%$ CI: 1.46-18.88), younger age category of farms (OR: 5.53; 90\% CI: 1.09-21.66), and farms with single breed of goats (OR: 8.50; 90\% CI: 1.27-41.97) [42]. 
Most of the studies in Asia and different parts of the world showed that introduction of new animals provided one of the highest risk factors for brucellosis in livestock farms, and this is an important risk factor for farmers to guide against to have brucellosis-free herds.

The trend of brucellosis in cattle in Malaysia showed $21.8 \%$ of sampled cattle were positive for Brucella antibodies and seropositive herds clustered around the central part of Peninsular Malaysia with a remarkable variation seen in the cattle-level seroprevalence, but the rate remained relatively low $(<5 \%)$. The chi-square statistics revealed that herd size $\left(\chi^{2}=1206.077, \mathrm{df}=2, \mathrm{p}=0.001\right)$, breed $\left(\chi^{2}=37.429\right.$, $\mathrm{df}=1, \mathrm{p}=0.001)$, month of sampling $\left(\chi^{2}=51.596, \mathrm{df}=11\right.$, $\mathrm{p}=0.001)$, year $\left(\chi^{2}=40.08, \mathrm{df}=8, \mathrm{p}=0.001\right)$, and state $\left(\chi^{2}=541.038, \mathrm{df}=10, \mathrm{p}=0.001\right)$ to be associated with increased Brucella seroposivity [43].

In Bangladesh, Brucellosis prevalence showed variation based on occupations of people $(2.5-18.6 \%)$ and species of animals (3.7\% in cattle, $4.0 \%$ in buffalo, $3.6 \%$ in goats and $7.3 \%$ in sheep). The prevalence of brucellosis also varied in livestock farmers (2.6$21.6 \%)$, milkers $(18.6 \%)$, butchers $(2.5 \%)$, and veterinarians $(5.3-11.1 \%)$ who have direct contact with animal and its products or who consume raw milk [44].

Thailand is still considered endemic for brucellosis and in recent years there have been concerted efforts beginning from 2009 to eradicate brucellosis in animals, but the high volume of goat movements hampers the test and slaughter and compensation policy from achieving the needed objectives [45]. An outbreak of brucellosis in a goat farm in Thailand led to a fatal infection of a 79-year-old goat farmer with unprotected exposure to goat carcasses identified as the main risk factor [46]. Farmers and veterinary personnel must be careful while handling animals in endemic areas.

\section{North America}

The United States of America have battled brucellosis over the years, but yet many parts of the country continue to experience and suffer from the effects of brucellosis mainly caused by B. abortus in cattle, elk, and bison. The elk is a very important animal in the epidemiology of the infection because it transmits it to cattle and feral swine are important reservoirs of the infection making eradication difficult because it can be maintained in the sylvatic cycle, especially in the Greater Yellowstone Area and Texas [47]. Similarly, Canada has failed to eradicate brucellosis in cattle which are usually infected by bison. A controversial plan to depopulate the bison population and introduce new disease free stock failed to get approval because of public outcry against the proposal [48]. The presence of brucellosis in wild life is a risk factor for the infection in domestic animals because of the constant encroachment of wild life into domestic animals and vice versa. Other countries in this region also have had their fair share of the economic and health impact of brucellosis. Mexico is endemic for brucellosis in spite years of control measures. A study in goats found a prevalence of $38 \%$ in Jalisco region and $11 \%$ in Michoacan region of Mexico with Michoacan showing lower odds of brucellosis (OR: $0.32 ; 95 \% \mathrm{CI}$ : 0.21-0.48) compared to Jalisco and goats in zero grazing had lower odds of brucellosis (OR: $0.22 ; 95 \% \mathrm{CI}$ : 0.09-0.57) compared to those in grazing systems [49].

\section{South America}

The countries of South America are known to be endemic for animal brucellosis. For example, Brazil has a large population of livestock but endemic brucellosis has led to economic losses and transmission of the disease from the animal to the human population in some cases [50]. The total economic loss due to brucellosis in a study in 2013 was estimated at 448 million US dollars [51].

\section{Europe}

Brucellosis has been a problem in some parts of Europe for many years. Countries such as Greece, Macedonia, Croatia, and Yugoslavia have suffered from brucellosis in their livestock population [52]. Turkey is also known to be endemic for brucellosis especially in the central, eastern, and southeastern Anatolian regions [53].

\section{Australia}

Brucellosis caused by $B$. suis is the only source of endemic brucellosis in Queensland where humans and animals have been infected [29]. Brucellosis caused by $B$. suis has been detected in New South Wales from feral pigs during 2012 to 2013 with a prevalence of $3 \%$ [30]. Brucellosis has been reported in camel rearing countries around the world except Australia and is more common in Old World Camels than New World Camels which seldom come down with brucellosis [54].

\section{Prospects for Control and Eradication}

Bovine brucellosis has been eradicated from some parts of the world such as New Zealand, Sweden, Denmark, Norway, Finland, Germany, UK, Netherlands, Belgium, Luxembourg, Austria, Switzerland, Canada, Japan, and New Zealand [55]. Nations, where the prevalence of brucellosis, are below $2 \%$ may attempt eradication policies but attaining a brucellosis free status may take many years to achieve like the Malaysian scenario which has taken some 30 years but yet the eradication status remained unchanged [41]. It is suggested that eradication procedures should include vaccination of healthy animals as wells as culling of seropositive animals, instead of relying solely on one method.

\section{One Health Approach to Brucellosis Control}

A very important approach to the control of brucellosis that is gaining more and more recognition around the world in recent years is the One Health approach. For effective control and possible 
eradication of brucellosis from both the human and animal population, it is important to note which species of Brucellae affect which animals and which animals can be reservoirs, especially in developing countries where mixed farming is common practice [56]. These reservoir animals are responsible for maintaining the infection and transmitting it to the human population. Brucella melitensis is the most pathogenic and the most common cause of serious infection. It is mainly found in small ruminants and can affect cattle in mixed farming methods. Sometimes cattle can be affected by both $B$. melitensis and B. abortus in mixed farming methods and the differentiation of the etiologic agent in human cases arising from such scenario may require more than serology; isolation and PCR are very helpful in identifying the exact species causing infection $[2,41,57]$. In the One Health framework veterinary, medical, environmental and allied professionals and experts collaborate together with the aim of identifying possible risk factors for this infection and design a suitable approach to combatting the infection. Unfortunately, in many underdeveloped and developing countries, this kind of collaboration is non-existent or weak which gives room for brucellosis to thrive unchecked especially in rural populations.

\section{Conclusion}

Brucellosis is widespread across the globe and though most infections occur in developing countries, the developed countries have not being spared the scourge of the disease as more and more reports of infection have been reported. The prevalence varies from country to country and region to region and is influenced by multiple factors. The common risk factors of brucellosis in humans include consumption of unpasteurized milk and dairy products, contact with aborted animal fetuses, hunting feral animals, and unhygienic practices. The common risk factors in animals include introduction of new animals into herds, high stocking density, large herd sizes of farms, mixed farming, and inadequate biosecurity. To eradicate the disease will require a combination of different measures including test and slaughter, vaccination, quarantine of suspected animals and on the human perspective stricter hygiene measures, minimum animal-human contact and consumption of only pasteurized milk and dairy products.

\section{Acknowledgment}

The Faculty of Veterinary Medicine, Universiti Malaysia Kelantan for providing a good atmosphere and facilities needed for this paper.

\section{Competing Interests} interests.

The author declares that he has no competing

\section{References}

1. Roushan MR, Kazemi S, Rostami FF, Ebrahimpour S. A study of Brucella infection in humans. Crescent J Med Biol Sci 2014;1:69-75.
2. Godfroid J, DeBolle X, Roop RM, O'Callaghan D, Tsolis RM, Baldwin C, et al. The quest for a true one health perspective of brucellosis. Rev Sci Tech 2014;33:521-38.

3. Foster G, Osterman BS, Godfroid J, Jacques I, Cloeckaert A. Brucella ceti sp. Nov. And Brucella pinnipedialis sp. Nov. For Brucella strains with cetaceans and seals as their preferred hosts. Int J Syst Evol Microbiol 2007;57:2688-93.

4. Ficht T. Brucella taxonomy and evolution. Future Microbiol 2010;5:859-66

5. Mirnejad R, Vahdati AR, Ahmadi A, Mortazavi SM, Piranfar V. Comparison of culture and multiplex PCR technique for detection of Brucella abortus and Brucella melitensis from human blood samples. Zahedan J Res Med Sci 2013;15:29-32

6. Steffen R. Antacids - A risk factor in travellers brucellosis? Scand J Infect Dis 1977;9:311-2.

7. Ladak K, Sitzer N, Wyne A, Ghadaki B, Patel A. Fever in the returning traveller: A forgotten culprit. Can J Infect Dis Med Microbiol 2014;25:194-5.

8. Hadda V, Khilnani G, Kedia S. Brucellosis presenting as pyrexia of unknown origin in an international traveller: A case report. Cases J 2009;2:7969.

9. Di Pierdomenico A, Borgia SM, Richardson D, Baqi M. Brucellosis in a returned traveller. CMAJ 2011;183:E690-2.

10. Seleem MN, Boyle SM, Sriranganathan N. Brucellosis: A re-emerging zoonosis. Vet Microbiol 2010;140:392-8.

11. Dean AS, Crump L, Greter H, Schelling E, Zinsstag J. Global burden of human brucellosis: A systematic review of disease frequency. PLoS Negl Trop Dis 2012;6:e1865.

12. Ducrotoy M, Bertu WJ, Matope G, Cadmus S, CondeÁlvarez R, Gusi AM, et al. Brucellosis in Sub-Saharan Africa: Current challenges for management, diagnosis and control. Acta Trop 2015. pii: S0001-706X30147-9.

13. Aworh MK, Okolocha E, Kwaga J, Fasina F, Lazarus D, Suleman I, et al. Human brucellosis: Seroprevalence and associated exposure factors among abattoir workers in Abuja, Nigeria - 2011. Pan Afr Med J 2013;16:103.

14. Regassa C, Mekonnen D, Yamuah L, Tilahun H, Guta T, Gebreyohannes A, et al. Human brucellosis in traditional communities in Ethiopia. Int J Trop Med 2009;4:59-64.

15. John K, Fitzpatrick J, French N, Kazwala R, Kambarage D, Mfinanga GS, et al. Quantifying risk factors for human brucellosis in rural northern Tanzania. PLoS One 2010;5:e9968.

16. Makita K, Fèvre EM, Waiswa C, Kaboyo W, De Clare Bronsvoort BM, Eisler MC, et al. Human brucellosis in urban and peri-urban areas of Kampala, Uganda. Ann N Y Acad Sci 2008;1149:309-11.

17. Nassaji M, Govhary A, Ghorbani R. Epidemiological, clinical and laboratory findings in adult patients with acute brucellosis: A case-control study. Acta Medica Mediterr 2015;31:1319-25.

18. Bamaiyi PH, Hassan L, Khairani-Bejo S, Krishnan N, Adzhar A, Ramlan M, et al. Risk factor for Brucellosis in urban and rural areas of Malaysia. In: UPM, editor. $2^{\text {nd }}$ Malaysia-Thailand Graduate Forum 2013 in Life Science, Food Science and Agriculture (MTGF) 2013. Serdang, Selangor, Malaysia: University Putra Malaysia; 2013. p. 139-40.

19. Khan MY, Mah MW, Memish ZA. Brucellosis in pregnant women. Clin Infect Dis 2001;32:1172-7.

20. Fuchs I, Osyntsov L, Refaely Y, Ciobotaro P, Zimhony O. Ritual slaughter as overlooked risk factor for brucellosis. Emerg Infect Dis 2016;22:746-8.

21. Hegazy YM, Ridler AL, Guitian FJ. Assessment and simulation of the implementation of brucellosis control programme in an endemic area of the Middle East. Epidemiol Infect 2009; $137: 1436-48$

22. Scharff RL. Economic burden from health losses due to foodborne illness in the United States. J Food Prot 2012;75:123-31.

23. Traxler RM, Guerra MA, Morrow MG, Haupt $T$, Morrison J, Saah JR, et al. Review of brucellosis cases 
from laboratory exposures in the United States in 2008 to 2011 and improved strategies for disease prevention. J Clin Microbiol 2013;51:3132-6.

24. Agrarias FD, De Vericel G, De Antioquia U. NIH public access. J Infect Dev Ctries 2013;6:675-9.

25. Gwida M, Neubauer H, Ilhan Z, Schmoock G, Melzer F, Nöckler K, et al. Cross-border molecular tracing of brucellosis in Europe. Comp Immunol Microbiol Infect Dis 2012;35:181-5.

26. Al Dahouk S, Nöckler K, Hensel A, Tomaso H, Scholz HC, Hagen RM, et al. Human brucellosis in a nonendemic country: A report from Germany, 2002 and 2003. Eur J Clin Microbiol Infect Dis 2005;24:450-6.

27. Mancini FR, Bella A, Graziani C, Marianelli C, MughiniGras L, Pasquali P, et al. Trends of human brucellosis in Italy, 1998-2010. Epidemiol Infect 2014;142:1188-95.

28. Aftab H, Dargis R, Christensen JJ, Le Flèche P, Kemp M. Imported brucellosis in Denmark: Molecular identification and multiple-locus variable number tandem repeat analysis (MLVA) genotyping of the bacteria. Scand J Infect Dis 2011;43:536-8.

29. Eales KM, Norton RE, Ketheesan N. Brucellosis in Northern Australia. Am J Trop Med Hyg 2010;83:876-8

30. Ridoutt C, Lee A, Moloney B, Massey P, Charman N, Jordan D. Detection of brucellosis and leptospirosis in feral pigs in New South Wales. Aust Vet J 2014;92:343-7.

31. Coelho AC, Díez JG, Coelho AM. Risk factors for Brucella spp. updates on brucellosis. In: Baddour MM, editor. Domestic and Wild Animals. InTech Publishers; 2015. p. 1-31.

32. Bamaiyi PH, Khairani-Bejo S, Zainal Abidin M. The economic impact attributable to brucellosis among goat farms in Peninsula Malaysia and cost benefit analysis. Res Opin Anim Vet Sci 2015;5:57-64.

33. Godfroid J, Scholz HC, Barbier T, Nicolas C, Wattiau P, Fretin D, et al. Brucellosis at the animal/ecosystem/human interface at the beginning of the $21^{\text {st }}$ century. Prev Vet Med 2011;102:118-31.

34. Bamaiyi PH, Hassan L, Khairani-Bejo S, Zainal MA. Updates on brucellosis in Malaysia and Southeast Asia. Malays J Vet Res 2014;5:71-82.

35. Adamu M, Mshelia GD, Elelu N, Ouda L, Egwu GO. Studies on farmer awareness on caprine abortion and the presence of Brucella abortus and Brucella melitensis in selected flocks in an arid zone of Nigeria. Vet Med 2012;4:17-21.

36. Sanogo M, Abatih E, Thys E, Fretin D, Berkvens D, Saegerman C. Risk factors associated with brucellosis seropositivity among cattle in the central savannah-forest area of Ivory Coast. Prev Vet Med 2012;107:51-6.

37. Mufinda FC, Boinas F, Nunes C. Prevalence and factors associated with cattle brucellosis in animal herds of the Namibe province in Angola. Alexandria J Vet Sci 2015;47:7.

38. Mwebe R, Nakavuma J, Moriyón I. Brucellosis seroprevalence in livestock in Uganda from 1998 to 2008: A retrospective study. Trop Anim Health Prod 2011;43:603-8.

39. Megersa B, Biffa D, Abunna F, Regassa A, Godfroid J, Skjerve E. Seroprevalence of brucellosis and its contribution to abortion in cattle, camel, and goat kept under pastoral management in Borana, Ethiopia. Trop Anim Health Prod 2011;43:651-6.

40. Musallam II, Abo-Shehada M, Omar M, Guitian J. Crosssectional study of brucellosis in Jordan: Prevalence, risk factors and spatial distribution in small ruminants and cattle. Prev Vet Med 2015;118:387-96.

41. Bamaiyi PH, Hassan L, Khairani-Bejo S, ZainalAbidin M, Ramlan M, Adzhar A, et al. The prevalence and distribution of Brucella melitensis in goats in Malaysia from 2000 to
2009. Prev Vet Med 2015;119:232-6.

42. Bamaiyi PH, Hassan L, Khairani-Bejo S, ZainalAbidin M, Ramlan M, Krishnan N, et al. Case-control study on risk factors associated with Brucella melitensis in goat farms in Peninsular Malaysia. Trop Anim Health Prod 2014;46:739-45.

43. Anka MS, Hassan L, Adzhar A, Khairani-Bejo S, Mohamad RB, Zainal MA. Bovine brucellosis trends in Malaysia between 2000 and 2008. BMC Vet Res 2013;9:230.

44. Islam MA, Khatun MM, Werre SR, Sriranganathan N, Boyle SM. A review of Brucella seroprevalence among humans and animals in Bangladesh with special emphasis on epidemiology, risk factors and control opportunities. Vet Microbiol 2013;166:317-26.

45. Inchaisri $\mathrm{C}$, Prasomsri $\mathrm{P}$, Boonserm $\mathrm{T}$, Hogeveen $\mathrm{H}$, Ajariyakajorn K. A stochastic simulation model for brucellosis eradication in goat flocks in an area with high flock prevalence but low animal prevalence. Small Rumin Res 2016;136:227-37.

46. Wongphruksasoong V, Santayakorn S, Sitthi W, Chuxnum T, Pipatjaturong N, Kunthu A, et al. An outbreak of Brucella melitensis among goat farmers in Thailand, December 2009. Outbreak Surveill Investig Rep 2012;5:14-21.

47. Higgins J, Stuber T, Quance C, Edwards WH, Tiller RV, Linfield T, et al. Molecular epidemiology of Brucella abortus isolates from cattle, elk, and bison in the United States, 1998 to 2011. Appl Environ Microbiol 2012;78:3674-84.

48. Shury TK, Nishi JS, Elkin BT, Wobeser GA. Tuberculosis and brucellosis in wood bison (Bison bison athabascae) in Northern Canada: A renewed need to develop options for future management. J Wildl Dis 2015;51:543-54.

49. Oseguera Montiel D, Frankena K, Udo H, Keilbach Baer NM, van der Zijpp A. Prevalence and risk factors for brucellosis in goats in areas of Mexico with and without brucellosis control campaign. Trop Anim Health Prod 2013;45:1383-9.

50. Meirelles-Bartoli RB, Mathias LA, Samartino LE. Brucellosis due to Brucella suis in a swine herd associated with a human clinical case in the State of São Paulo, Brazil. Trop Anim Health Prod 2012;44:1575-9.

51. Santos RL, Martins TM, Borges ÁM, Paixão TA. Economic losses due to bovine brucellosis in Brazil. Pesqui Vet Bras 2013;33:759-64.

52. Taleski V, Zerva L, Kantardjiev T, Cvetnic Z, Erski-Biljic M, Nikolovski B, et al. An overview of the epidemiology and epizootology of brucellosis in selected countries of Central and Southeast Europe. Vet Microbiol 2002;90:147-55.

53. Yilmaz B, Ozdemir G, Aktas E, Komur B, Alfidan S, Memisoglu $\mathrm{S}$, et al. Brucellosis suspicion is the most important criterion for diagnosis particularly in endemic regions. Open Orthop J 2016;10:7-11.

54. Wernery U. Camelid brucellosis: A review. Rev Sci Tech 2014;33:839-57.

55. Bosilkovski M. Brucellosis: It is not only Malta! In: Zoonoses-Infections Affecting Humans and Animals. Dordrecht: Springer; 2015. p. 287-315

56. Godfroid J, Al Dahouk S, Pappas G, Roth F, Matope G, Muma J, et al. A "one health" surveillance and control of brucellosis in developing countries: Moving away from improvisation. Comp Immunol Microbiol Infect Dis 2013;36:241-8

57. Bamaiyi PH, Hassan L, Khairani-Bejo S, Zainal MA, Ramlan M, Krishnan N, et al. isolation and molecular characterization of Brucella melitensis from seropositive goats in Peninsular Malaysia. Trop Biomed 2012;29:1-6. 